\title{
Further Studies on the Microbial Content (Endomicrobiology, Endobacteriology) of Fruit and Vegetable Crops: the Study Continues!
}

\author{
Jack R. Edelman ${ }^{1} \&$ Yue J. Lin $^{2}$ \\ ${ }^{1}$ Department of Science, Borough of Manhattan Community College, City University of New York, 199 \\ Chambers Street, New York, New York 10007, USA \\ ${ }^{2}$ Department of Biological Sciences, Saint John's University, 8,000 Utopia Parkway, Jamaica, New York, 11439, \\ USA \\ Correspondence: Jack R. Edelman, Department of Science, Borough of Manhattan Community College, City \\ University of New York, 199 Chambers Street, New York, NY, 10007, USA. E-mail: \\ themadprofessor47@hotmail.com
}

Received: January 4, 2019

Accepted: January 24, 2019 Online Published: February 13, 2019

doi:10.5539/jfr.v8n2p42

URL: https://doi.org/10.5539/jfr.v8n2p42

\begin{abstract}
Previous studies in our lab over the past several years on fruits and vegetables have identified various species of microorganisms, primarily bacteria, that appear to be endemic to the inner flesh/pulp of many crops. While consumption of these fruits and vegetables usually do not cause disease to the public in general, there may be a greater risk to immunocompromised individuals, especially upon consumption of crops that are eaten raw/uncooked or only slightly cooked. In this study, we examined various fruits, herbs, and vegetables that we had not previously examined for the presence of such microorganisms, and many/most of the crops we examined did indeed contain endemic microorganisms in their inner flesh/pulp. Our findings are herewith reported.
\end{abstract}

Keywords: bacteria, microorganisms, fruits, vegetables, crops, endomicrobiology

\section{Introduction}

Over the past several years have identified numerous species of microorganisms that inhabit the surface and/or flesh/pulp of various fruit and vegetable crops; terms we have coined topomicrobiology and endomicrobiology, respectively (Edelman and Lin 2011, 1013, 2016). These microorganisms were generally considered to be non-pathogenic commensal species, although in certain instances, such as immunocompromised individuals, some of these species can theoretically become opportunistic and pathogenic. We have continued this study to crops that we had not previously tested, and we hereby present the results in this report. Among the crops currently investigated are fruits and vegetables, edible mushrooms/fungi, aromatic/culinary herbs and spices, and some uncommon and tropical fruits and vegetables.

\section{Materials \& Methods}

The microbial content of crops was isolated and identified using a combination of the methods previously described (Edelman and Lin (2011, 2013, 2016). These included inserting sterile cotton-tipped applicators into the flesh/pulp and/or homogenizing the crops or small sections of crops into blenders/food processors for one minute. Tryptic Soy agar plates (or in some cases, Saboraud agar plates, for fungal cultivation ) were then swabbed with cotton tipped applicators and allowed to grow at room temperature for several days. Plates were then shipped to AvistaPharma Solutions, 104 Gold Street, Agawam, Massachusetts, 01001, U.S.A. for species identification using DNA sequence analysis.

\section{Results and Discussion}

While some crops were found to be sterile/microorganism-free in the inner flesh/pulp, many were indeed found to harbor bacteria and in some cases fungi. The bacterial/fungal content of such crops are shown in Table 1 . 
Table 1. Microbial species found in the inner flesh/pulp of crops tested in this study

\begin{tabular}{|c|c|}
\hline Crop: & Species present: \\
\hline \multirow{4}{*}{ Sage (Salvia officinalis) } & Enterobacter cowanii \\
\hline & Ignatzschineria indica \\
\hline & Brachybacterium sp. \\
\hline & Pseudomonas fulva \\
\hline Oregano (Origanum vulgare) & Myroides odoratimimus \\
\hline Dandelion (Taraxicum officinale) & Staphylococcus epidermidis \\
\hline \multirow{2}{*}{\multicolumn{2}{|c|}{$\begin{array}{l}\text { Green Ong Choy/Water Spinach } \\
\text { (Ipomoea aquatica) }\end{array}$}} \\
\hline & Enterobacter asburiae \\
\hline \multicolumn{2}{|l|}{ Thyme (fresh,not dried) } \\
\hline \multirow[t]{3}{*}{ (Thymus vulgaris) } & Pseudomonas straminea \\
\hline & Pseudomonas fulva \\
\hline & Microbacterium sp. \\
\hline \multicolumn{2}{|l|}{ Rosemary (fresh, not dried) } \\
\hline \multirow[t]{3}{*}{ (Rosemarinus officinalis) } & Bacillus subtilis \\
\hline & Pantoea agglomerans \\
\hline & Pantoea dispersa \\
\hline Catnip (Neperta cataria) & Acinetobacter sp. \\
\hline (used by humans as an herbal tea, & Exiguobacterium acetylicum \\
\hline and culinary herb) & Enterobacter kobei \\
\hline Arugula /Rocket, Garden Rocket, & Citrobacter freundii \\
\hline Rugula, Rucola Colewort, Roquette & Alcaligenes faecalis \\
\hline (Eruca sativa) & Corynebacterium variabile \\
\hline Vanilla ("beans" and pods) & Bacillus subtilis \\
\hline & Bacillus amyloliquefaciens \\
\hline Arrowhead Bulb (tuber)/Duck potato/ & Chryseobacterium sp. \\
\hline Katniss/Omodaka,swamp potato/tule & Stenotrophomonas maltophilia \\
\hline potato/wapato & Pseudomonas fluorescens \\
\hline (Sagittaria sagittifolia) & Stenotrophomonas sp. \\
\hline Soursop/Guanabana/graviola & Pantoea agglomerans \\
\hline \multirow[t]{4}{*}{ (Annona muricata) } & Enterobacter pyrinus \\
\hline & Erwinia sp. \\
\hline & $\begin{array}{l}\text { Fungus: Aspergillus sp., (either A. } \\
\text { oryzae (or) }\end{array}$ \\
\hline & A. parasiticus (or) A. terricola) \\
\hline Red Currant & Curtobacterium flaccumfaciens \\
\hline (Ribes rubrum) & Pantoea agglomerans \\
\hline \multirow{4}{*}{ (Rubus ursinus X Rubus idaeus) } & Glucanobacter cerinus \\
\hline & Candida railenensis (yeast) \\
\hline & Bacillus altitudinis \\
\hline & Geotrichum candidum \\
\hline Nance Yellow Cherry & Acidovorax temporans \\
\hline \multirow{2}{*}{ (Brysonima crassifolia) } & Sphingomonas paucimobilis \\
\hline & Sphingomonas abaci \\
\hline Betel leaf/Paan/Lalot & Pseudomonas oryzihabitans \\
\hline (Piper betle) & Rhizobium sp. \\
\hline Watercress (Nastiurtium officinale) & Providencia rettgeri \\
\hline Green Olive (fresh) & Lysinibacillus alkalisoli \\
\hline Black Olive (semi-dried) & Providencia rettgeri \\
\hline \multirow[t]{3}{*}{ (Olea europaea) } & Enterobacter kobei \\
\hline & Achromobacter spanius \\
\hline & Delftia acidovorans \\
\hline
\end{tabular}




\author{
Tarragon/Estragon \\ (Artmisia dracunculus) \\ Lily Flowers (dried, packaged in \\ cellophane, imported from China) \\ (Hemerocallis fulva) \\ Swiss Chard (Beta vulgaris)
}

Feijoa (Acca sellowiana)

Stuffer/Stuffing Mushroom/Large White

Button Mushroom (Agaricus bisporus )

Shitake Mushroom (Lentinula edodes)

Seafood Mushroom/Enoki Mushroom/

Enokitake/Gold Needle Mushroom

(Flammulina velutipes)

Bunapi Mushroom/White Beech Mushroom/

Brown Beech Mushroom

(Hypsizygus tessellatus)

King Oyster Mushroom (Pleurotus eryngii)

Oyster Mushroom (Pleurotus ostreatus)

Black Fungus/Tree Ear Fungus/Black Chinese

Fungus/Wood Fungus/Ear Fungus/Tree Ear Fungus

(Auricularia polytricha/Hirneola polytricha)

Morel (Morchella esculenta)

Alfalfa Sprouts (Medicago sativa)

Peas (in pods/out of pods) (Pisum sativum)

Brown Russian Cucumber (Cucumis sativus)

Red Water Lily (Nymphaea nouchali)

(Southeast Asian food plant)

Dill (Anethum graveolens)

Mint (Mentha sp.)

Basil/Sweet Basil (Ocimum basilicum)

Peanuts (Raw, Green) (Arachis hypogaea)

Rose Hips (freshly harvested) (Rosa rugosa)

Garbanzo Bean/Chick Pea (Cicer arietinum)

String Bean/Green Bean/Snap Bean

(Phaseolus vulgaris)

Long Bean/Asparagus Bean/Chinese Long Bean/
Exiguobacterium acetylicum

Staphylococcus hominus

Bacillus cibi

Bacillus flexus

Bacillus amyloliquefaciens

Bacillus megaterium

Acinetobacter johnsonii

Pseudomonas chlororaphis

Exiguobacterium actylicum

Methylobacterium hispanicum

Stphylococcus hominis

Many Fungal colonies: Penicillium

camemberti (or)

P. clavigerum (or) P.crustosum (or) P.

commune (or)

P. corylophilum

Pseudomonas fluorescens

Trichococcus collinsii

Ewingella americana

Serratia grimesii

Achromobacter spaniu

Serratia liquefaciens

Enterococcus avium

Serrtatia quinivorans

Pseudomonas extremorientalis

Ewingella americana

Staphylococcus pasteuri

Pseudomonas fluorescens

Bacillus thuringiensis

Serratia liquefaciens

Enterococcus casseliflavus

Pseudomonas tolaasii

Enterobacter cancerogenus

Stenoitrophomonas maltophilia

Escherichia hermanii

Enterobacter cancerogenus

Beutenbergia cavernae

Microbacterium oleivorans

Klebsiella pneumoniae

Enterobacter sp.

Enterobacter cowanii

Lysinibacillus sp.

Morganella sp.

Pseudomonas pseudoalcaligenes

Serratia fonticola

Pseudomonas aeroginosa

Serratia marcescens

Pseudomonas mosselii

Psychrobacillus sp.

Pseudomonas oryzihabitans

Curtobacterium flaccumfaciens

Staphylococcus epidermidis

Arthrobacter sp.

Microbacterium esteraromaticum

Pantoea agglomerans 


\author{
Yard Long Bean/Snake Bean \\ (Vigna unguiculata) \\ Jamaican Naseberry/Sapodilla (Manikara zapota) \\ Cilantro/Coriander/Chinese Parsley \\ (Coriandrum sativum)
}

Red Amaranth (Amaranthus cruentus)

Malabar Spinach (Basella rubra/B. alba)

Mustard Greens (Brassica juncea)

Seaside Grape/Sea Grape/Bay Grape/

Beach Grape (Coccoloba uvifera)

Ba Cha/ Bac Ha/ Ba Ha/ Taro Stem/

Elephant Ear Plant Stem

(Colocasia gigantea)

Lemon Grass (Cymbopogon citratus)

Portobello Mushroom

(Agaricus bisporus)

Bamboo Shoots (raw, fresh)

(Bambusa vulgaris)

Jackfruit (Artocarpus heterophyllus)

Vietnam Garland Chrysanthemum/Edible

Chrysanthemum (Glebionis coronaria)

Asparagus Lettuce/Celtuce/Stem Lettuce/

Celery Lettuce/Chinese Lettuce

(Lactuca sativa var. augustana)

Cremini Mushroom

(Agaricus bisporus)
Pseudomonas fulva

Klebsiella pneumoniae

Exiguobacterium acetylicum

Phacidium sp. (Fungus)

Pseudomonas sp.

Stenotrophomonas sp.

Bacillus thuringiensis

Myroides odoratus

Arthrobacter nicotianae

Arthrobacter sp.

Pantoea agglomerans type 3

Arthrobacter pascens

(Arthrobacter histidinolovorans (or)

Arthrobacter nicotinovorans)

Coccoloba uvifera acetylicum

Exiguobacterium acetylicum

Aeromicrobium fastidiosum

Rhodococcus fascians

Micrococcus sp.

Pantoea dispersa

Rhodococcus corynebacterioides

Micrococcus sp.

Staphyloccuc cohnii

Fungus/mold: (unidentifiable)

Klebsiella pneumoniae

Stenotrophomonas sp.

Pseudomonas monteilii

Acinetobacter baumannii complex

Pseudomonas brenneri

(or) Pseudomonas fluorescens

Alcaligenes faecalis

Exiguobacterium sp.

Pseudomonas monteilii

Enterobacter kobei

Pseudomonas sp.

Exiguobacterium acetylicum

Pantoea sp.

Pseudomonas fulva

Myroides odoratimimus 
Table 2. Fruit and Vegetable species in which the inner flesh/pulp was test:d and found to be sterile:

\begin{tabular}{l}
\hline Watermelon (Golden Midget) (Citrullus lanatus) \\
\hline Persimmon (Hachiya and Jiro cultivars) (Diospyros kaki) \\
Tejocote/Manzanita/Mexican Hawthorn (Crataegus mexicana) \\
Jocote Fruit/Mombin/Hog plum/Ciruela (Spondias purpurea) \\
Fava Bean(Vicia faba) \\
Drumstick Tree Pods (Moringa oleifera) \\
Loquat (Eryobotrya japonica) \\
Snake Gourd/Serpent Gourd(Trichosanthes cucumerina) \\
Chestnut(Castanea dentata) \\
Banana Blossom/BananaFlower (Musa acuminata Colla) \\
Sour Cherry/Montmorency Cherry(Prunus cerasus) \\
Ivory Gaya Melon (Cucumis melo inodorus 'Ivory Gaya') \\
Mango (Red \& Yellow varieties) (Mangifera indica) \\
Indian Jujube/Ber Fruit/Chinese Date/Chinese Apple/Indian Plum/ \\
Reji Pandu (Ziziphus mauritiana) \\
Carob/St. John's Bread/Locust Bean (Ceratonia siliqua) \\
Goldenberry/Cape Gooseberry/Pichuberry/ \\
Peruvian Ground Cherry (Physalis peruviana) \\
\hline
\end{tabular}

Although most of the fruits and vegetables tested did contain one or several species of bacteria and fungi in their inner pulp/flesh, in general consumption of these crops with these organisms do not seem to cause human diseases. Many of these microorganisms are probably destroyed by hydrochloric acid and enzymes throughout our digestive system, while others are destroyed through the cooking process. However, immunocompromised individuals are most likely to be at a higher risk for infection, especially when these crops are eaten raw. In our previous study we noted numerous diseases that the microorganisms found in crops were capable of causing (Edelman and Lin, 2016), although their presence in fruits and vegetables do not necessarily cause infection. The purpose of this and our previous reports are merely to alert the consumers that these microorganisms are indeed present in such foods. Many consumers erroneously assume that if fruits and vegetables are washed before consumption they are automatically sterile, which we have shown not to be the case.

Another question which arises often is whether the organisms identified in the crops studied are pathogenic at all. While it is not the scope or objective of this report to investigate the possible pathogenicity of every organism identified, we have randomly selected a few species and canvassed the literature. We noted that almost all organisms identified in the fruits and vegetables can, under certain conditions, such as being immunocompromised, cause diseases and bacteremia. Providencia rettgeri, for example, (found in this study in watercress and green olives), have been found to cause bacteremia and bacteriuria (Wie, 2015). Bacillus flexus, (found in this study in dried lily flowers), has been found in an outbreak in a tertiary burn center (Ucar et al, 2016). Acidovorax, (found in this study in Nance yellow cherry), has been found in a case of sepsis (Shetty, et al., 2005). Curtobacterium flaccumfaciens, (found in this study in red currants), has been found in human infections (Funke, et al., 2005). Enterobacter pyrinus,( found in this study in soursop/guanabana), has also been found in human infections (Baylis et al., 2011). Myroides odorotimimus (found in this study fresh, undried oregano), has been found to cause bacteremia in a diabetic patient (Endicott et al., 2015) as well as soft tissue infections, septic shock, and pneumonia in other patients (Benedetti, et al., 2011). Ignatzschineria indica, (found in this study in the herb sage), has been implicated in Myiasis (Barker, et al., 2014). Infections involving Acinetobacter baumanii, (found in this study in lemon grass and catnip), have also been reported (Peleg et al., 2008). Pseudomonas chlororaphis, (found in this study in Swiss Chard), has been implicated in various human infections as reported by Faccone, et al., (2014). Further investigation of the literature on the other microbial species present in the fruits and vegetables used in this study will most likely also identify some cases of human infection. Again, this does not necessarily imply that such crops are dangerous to human health in general, but that they may, under certain circumstances, pose a risk to immunocompromised individuals.

\section{Conclusions}

The main idea of this report is to inform the public and scientific community that while some fruits and vegetables do seem to be sterile, many or most are not sterile, even after washing, as microorganisms are indeed present in their inner flesh/pulp. We plan to continue this investigation on other fruits and vegetables in the near 
future.

\section{Acknowledgments}

We wish to thank the following faculty/staff members of the Department of Science, Borough of Manhattan Community College, The City University of New York, for their help in providing materials for this investigation: Ms. Carmen Rivera, College Laboratory Technician, Professor Christopher Thompson, Professor Faisel Adem, and the late Professor Owen Meyers. We also wish to thank AvistaPharma Solutions, Agawam, Massachusetts, USA, for their microbial identification via DNA sequence analysis.

\section{References}

Baylis, C., Uyttendaele, M., Joosten, H., \& Davies, A., (2011). The Enterobacteriaceae and their significance to the food industry. Int'l. Life Sciences Institute (ILSI) Europe Report Series, December 2011.

Barker, H. S., Snyder, J. W., Hicks, A. B., Yanoviak, S. P., Southern, P., Dhakal, B. K., Ghimire, G. R., \& Couturier, M. R. (2014). First case reports of Ignatzschineria (Schineria) indica associated with myiasis. $J$. Clin. Microbiol, 52, 4432-4434. https://doi.org/10.1128/JCM.02183-14

Benedetti, P., Rassu, M., Pavan, G., Sefton, A., \& Pellizzer, G. (2011). Septic shock, pneumonia, and soft tissue infection due to Myroides odoratimimus: report of a case and review of Myroides infections. Infection, 39, 161-165. https://doi.org/10.1007/s15010- 010-0077-1

Edelman, J. R., \& Lin, Y. J. (2011). Microbiology of melons, cucumbers, and Squash (Cucirbitaceae) and related fruits. Int. J. of Food Science, Technology, \& Nutrition, 5(1), 51-65.

Edelman, J. R., \& Lin, Y. J. (2014). Microbiology of root crops, edible corms, tubers, bulbs, and rhizomes: an endobacteriological study. Int'l. J. Nutr. And Food Sci., 3(2), 69-72. https://doi.org/10.11648/j.ijnfs.20140302.18

Edelman, J. R., \& Lin, Y. J. (2016). Microbiology (endobacteriology) of fruit and vegetable crops: an expanded and continuing study. Int'l. J. Nutr. And Food Sci., 5(2), 95-104. https://doi.org/10.11648/j.ijnfs.20160502.12

Endicott-Yazdani, T. R., Dhiman, N., Benavides, R., \& Spak, C. W. (2015). Myroides odoratimimus bacteremia in a diabetic patient. Proc (Bayl Univ Med Cent), 28, 342-343. https://doi.org/10.1080/08998280.2015.11929268

Faccone, D., Pasteran, F., Albernoz, E., Gonzalez, L., Veliz, O., Prieto, M., Bucciarelli, R., Callejo, R., \& Corso, A. (2014). Human infections due to Pseudomonas chlororaphis and Pseudomonas oleovorans harboring new bla(VIM-2)-borne integrons. Infect Genet Evol., 28, 276-277. https://doi.org/10.1016/j.meegid.2014.10.012

Funke, G., Aravena-Roman, M., \& Frodl, R. (2005). First description of Curtobacterium spp. Isolated from human clinical specimens. J Clin Microbiol., 43, 1032-1036. https://doi.org/10.1128/JCM.43.3.1032-1036.2005

Peleg, A. Y., Seifert, H., \& Paterson, D. L. (2008). Acinetobacter baumanii: emergence of a successful pathogen. Clin Microbiol Reviews, 21, 538-582. https://doi.org/10.1128/CMR.00058-07.

Shetty, A., Barnes, R. A., Healy, B., \& Groves, P. (2005). A case of sepsis caused by acidovorax. J Infection, 51, e171-e172. https://doi.org/10.1016/j.jinf.2004.12.014

Ucar, A. D., Ergin, O. Y., Avci, M., An, A., Yildirim, M., \& Erkan, N., (2016). Bacillus flexus outbreak in a tertiary burn center. Burns, 42, 948-949. https://doi.org/10.1016/j.burns.2016.01.004

Wie, S-H. (2015). Clinical significance of Providencia bacteremia or bacteriuria. Korean J Intern Med., 30, 161-169. https://doi.org/10.3904/kjim.2015.30.2.167

\section{Copyrights}

Copyright for this article is retained by the author(s), with first publication rights granted to the journal.

This is an open-access article distributed under the terms and conditions of the Creative Commons Attribution license (http://creativecommons.org/licenses/by/4.0/). 